\title{
NO. 145
}

JULY

2020

\section{KEY POINTS}

- Total quality management or quality management systems have replaced the ad hoc quality control or quality assurance processes.

- Implementation of quality in health services requires a step-by-step, systematic, and comprehensive approach with full commitment of management and implementation of a practical road map.

- Development and execution of a quality framework is feasible through management commitment, adoption of standards, training of human resources for health in executing the standards, documentation of processes, and undertaking assessment.

- Quality is implementable only through concerted, sustained, and coordinated efforts by the national authorities, health system, and communities. Quality costs, but poor quality costs more.

\section{Quality Implementation on Urban Health Care Services in India'}

\author{
Sonalini Khetrapal \\ Social Sector Specialist \\ South Asia Regional Department \\ Asian Development Bank
}

\author{
Rajesh Bhatia \\ Senior Public Health Consultant \\ Asian Development Bank
}

\section{"The very first requirement in a hospital is that it should do the sick no harm." Florence Nightingale}

The famous statement of Florence Nightingale that a hospital should do the sick no harm is true even today. ${ }^{2}$ Health care services are expected to treat patients through therapeutic services that are not only evidence-based and effective but also safe. Efficacy and safety of health services are two pillars of quality health services. Inadequacies in either of these have the potential to cause unwanted delays in the resolution of illness and may result in undesirable harm to the patients.

\section{IMPACT OF POOR QUALITY ON HEALTH SERVICES}

Despite huge investments, health services remain far from perfect in developed and developing countries alike. In high-income countries, $7 \%$ of hospitalized patients acquire a health care-associated infection. In developing countries, this figure rises to $10 \%$. These infections can be easily avoided through better hygiene and rational infection control practices. ${ }^{3}$

A large number of patients do not receive appropriate, evidence-based care. ${ }^{4}$ The goal set by the World Health Assembly in 2003 of immunizing $75 \%$ of people with the influenza vaccine by 2010 is yet to be achieved. ${ }^{5}$ Irrational use of antibiotics

Comments from J. N. Srivastava, Advisor Quality Improvement, National Health Systems Resource Centre; and Cigdem Akin, Senior Public Management Economist, ADB are gratefully acknowledged.

2 Nightingale, F. 1863. Notes on Nursing: What It Is, and What It Is Not.

https://digital.library.upenn.edu/women/nightingale/nursing/nursing.html.

3 Pittet, D. and L. Donaldson. 2005. Clean Care is Safer Care: A Worldwide Priority. Lancet. 366. pp. 1246-7.

4 McGlynn, E. A. et al. 2003. The Quality of Health Care Delivered to Adults in the United States. New England Journal of Medicine. 348 (26). pp. 2635-45.

5 Organisation for Economic Co-operation and Development. 2015. Health at a Glance 2015: OECD Indicators. Paris.
ISBN 978-92-9262-275-6 (print) ISBN 978-92-9262-276-3 (electronic) ISSN 2071-7202 (print) ISSN 2218-2675 (electronic) Publication Stock No. BRF200197-2 DOI: http://dx.doi.org/10.22617/BRF200197-2 
in health facilities has accelerated selection and spread of antimicrobial resistance, which has become a major public health issue. ${ }^{6}$ Globally, the cost associated with medication errors is estimated at $\$ 42$ billion annually, not counting lost wages, foregone productivity, or health care costs. ${ }^{7}$

The World Health Organization estimates that 303,000 mothers and 2.7 million newborn infants die annually around the time of childbirth, and that many more are affected by preventable illness. Further, some 2.6 million babies are stillborn each year. ${ }^{8}$ Nearly $40 \%$ of health care facilities in low- and middle-income countries lack improved water, and about $20 \%$ lack sanitation. ${ }^{9}$

Poor quality care disproportionately affects the more vulnerable groups in society. The economic and social costs of patient harm caused by long-term disability, impairment, and lost productivity amount to trillions of dollars each year. ${ }^{10}$ In addition, duplicate services, ineffective care, and avoidable hospital admissionsfeatures of many health systems-generate considerable waste. Up to a fifth of health resources are deployed in ways that result in very few health improvements. These scarce resources could be deployed much more effectively in expanding and improving quality of health services. ${ }^{11}$

The urban poor constitute one of the important components of the vulnerable populations that find it a challenge to avail of quality health services. They need a strong policy articulation followed by implementation of access to safe and quality curative and preventive services to facilitate and augment their productivity.

\section{BENEFITS OF QUALITY IN URBAN HEALTH CARE}

Several benefits accrue in urban health with quality services. These services can be provided through strengthening the quality of health care services.

\section{WHAT IS QUALITY?}

There are several definitions of quality. According to the International Organization for Standards (ISO), ${ }^{12}$ quality is the totality of characteristics of an entity that bear on its ability to satisfy stated and implied needs.
Quality is the degree of congruence between expectation and realization: the matching of what you want with what you get. Quality is also defined as the meeting of predetermined user requirements for a particular substance or service. The predetermined requirements are known as "standards." Simply said, meeting standards is quality.

Quality is not a one-time activity. It is associated with consistency. This means providing the same product or service time after time, thereby making the outcome more predictable every time.

\section{EVOLUTION OF QUALITY SYSTEMS}

Initially, quality control of the final product or service was considered adequate. Subsequently, processes that converted inputs into outputs were brought under the ambit of promoting quality. This was called quality assurance. Active engagement of management in all aspects of implementation of quality is the current norm and known as total quality management or quality management system (Figure 1).

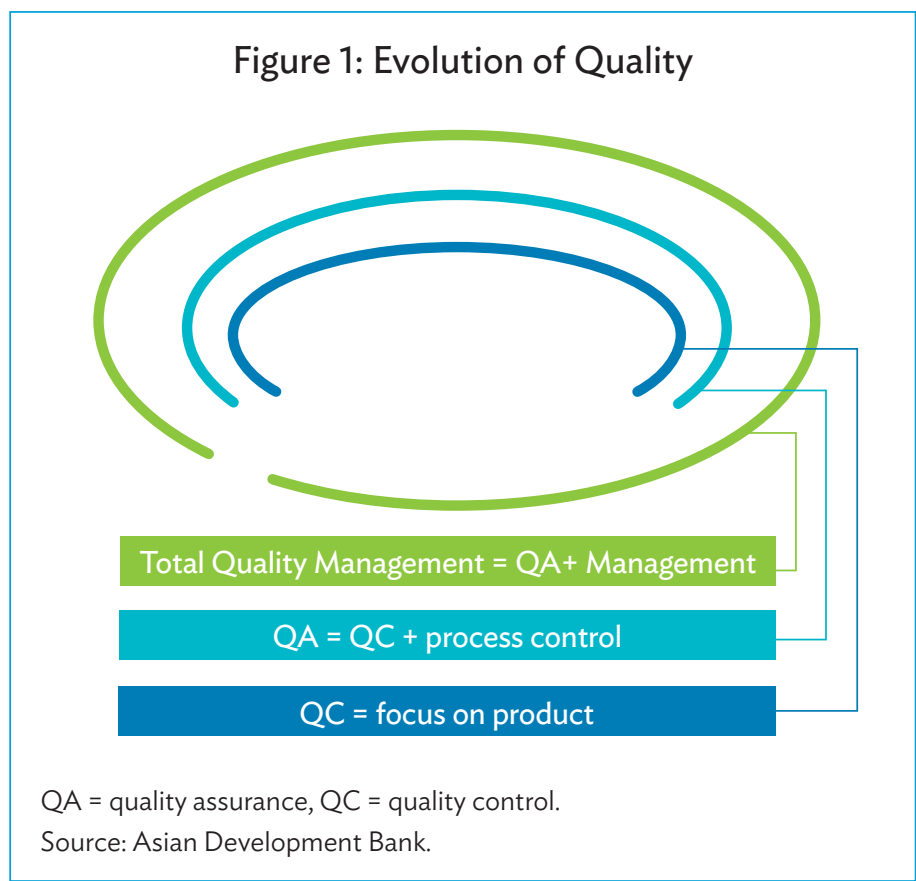

6 World Health Organization. 2018. WHO Fact Sheet on Antimicrobial Resistance. Geneva.

https:/www.who.int/news-room/fact-sheets/detail/antimicrobial-resistance (accessed 24 January 2020).

7 IMS Institute for Health Care Informatics. 2013. Advancing the Responsible Use of Medicines: Applying Levers for Change.

http://papers.ssrn.com/sol3/papers.cfm?abstract_id=2222541.

8 World Health Organization. 2016. World Health Statistics 2016: Monitoring Health for the Sustainable Development Goals. Geneva.

https://www.who.int/gho/publications/world_health_statistics/2016/EN_WHS2016_TOC.pdf?ua=1; and Lawn, J. E. et al. 2016. Stillbirths: Rates, Risk Factors, and Acceleration Towards 2030. Lancet. 387 (10018). pp. 587-603. doi:10.1016/S0140-6736(15)00837-5.

9 World Health Organization. Water, Sanitation and Health. https://www.who.int/water_sanitation_health/en/ (accessed 24 January 2020).

10 Slawomirski, L., A. Auraaen, and N. Klazinga. 2017. The Economics of Patient Safety: Strengthening a Value-Based Approach to Reducing Patient Harm at National Level. OECD Health Working Paper. No. 96. Paris: Organisation for Economic Co-operation and Development.

11 Organisation for Economic Co-operation and Development. 2017. Tackling Wasteful Spending on Health. Paris. https://doi.org/10.1787/9789264266414-en.

12 International Organization for Standardization. Fact Sheet. https://www.resourcesforlife.com/library/organizations/iso/ (accessed 5 July 2020). 
Figure 2: Deming Cycle

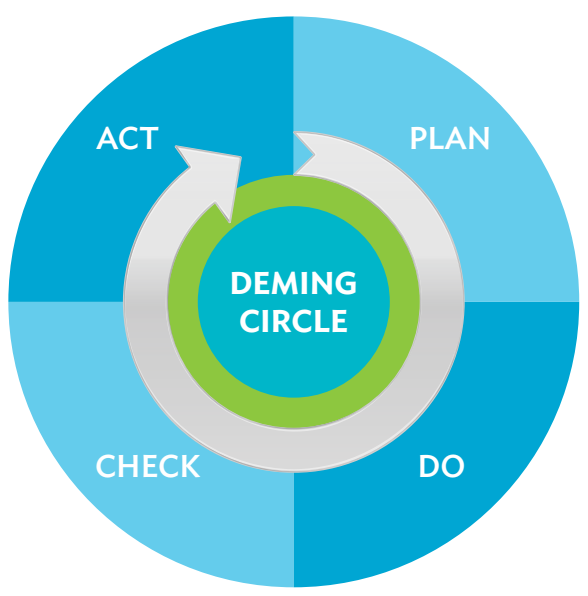

Source: American Society for Quality. What is the Plan-Do-Check-Act (PDCA) Cycle? https://asq.org/quality-resources/pdca-cycle (accessed 15 January 2020).

\section{QUALITY IS A JOURNEY, NOT A DESTINATION}

The Deming cycle illustrates the important principle of continuous improvement. Quality is not a static thing. The cycle of continuously planning $(P)$, doing $(D)$, checking $(C)$, and acting $(A)$ is essential to ensure that the quality cycle keeps turning, and that quality improves continuously (Figure 2).

The Deming cycle illustrates the need for continual momentum to go forward and upward. If there is no progress forward, the pressure is to fall backward-down the slope-with consequent loss of quality. Continuous quality improvement, therefore, comprises a set of activities that organizations should routinely carry out in order to enhance quality. It emphasizes the need for continuous improvement rather than error correction only. All aspects of hospital operations are explicitly targeted for improvement in a sequential manner.

\section{ELEMENTS OF HEALTH CARE QUALITY}

The Institute of Medicine, Washington, DC has suggested several elements of health care quality that together give a completeness to the quality in health care services. These are depicted in Figure 3.

\section{STEP-BY-STEP APPROACH IN DEVELOPING A QUALITY SYSTEM}

The development of a quality system is not an ad hoc process. It can be done only in a step-by-step manner as shown in Table 1.
Figure 3: Elements of Health Care Quality

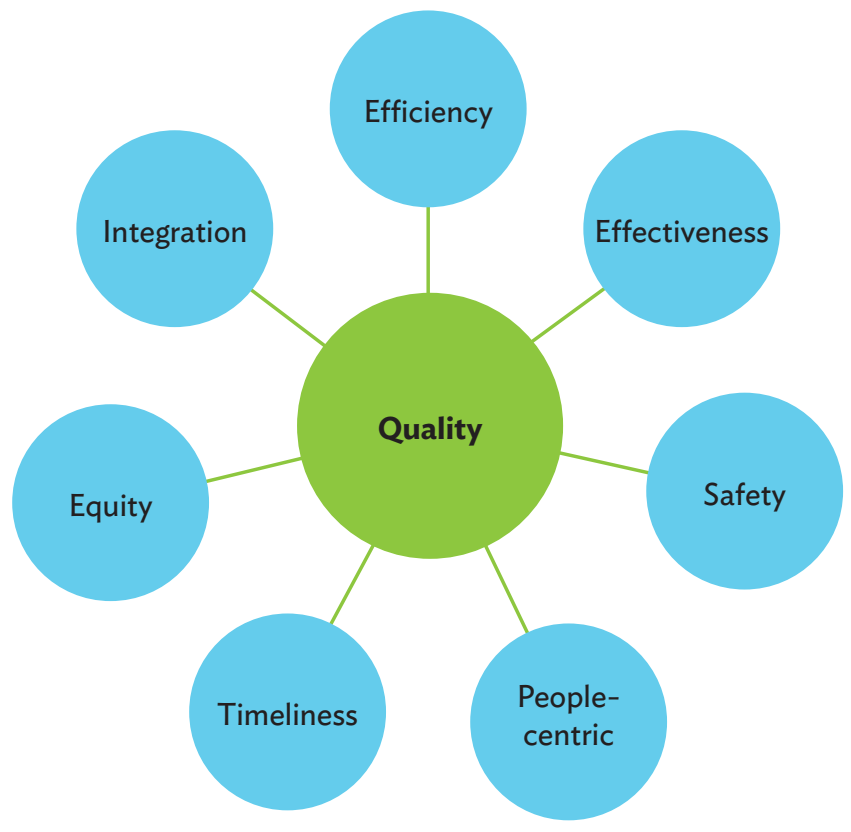

Source: Adapted from Institute of Medicine Committee on Quality of Health Care in America. 2001. Crossing the Quality Chasm-A New Health System for the 21st Century. Washington, DC: National Academies Press.

\section{Table 1: Step-by-Step Approach to Development of Quality Systems in Urban Health}

\begin{tabular}{lll}
\hline Quality policy & Mission statement \\
Quality plan & $\begin{array}{l}\text { Implementation of } \\
\text { policy }\end{array}$ \\
Quality manual & $\begin{array}{l}\text { Policy, plan, and } \\
\text { application of standards }\end{array}$ \\
\hline Procedures & $\begin{array}{l}\text { Development and } \\
\text { application of SOPs }\end{array}$ \\
Work instructions & $\begin{array}{l}\text { Methodology to carry } \\
\text { out specific tasks }\end{array}$ \\
\hline Training of staff on procedures & $\begin{array}{l}\text { Implementation of } \\
\text { quality system }\end{array}$ \\
and documentation & $\begin{array}{l}\text { Use of SOPs } \\
\text { Standardization of processes }\end{array}$ & $\begin{array}{l}\text { Assessment of quality } \\
\text { and improvement } \\
\text { process }\end{array}$ \\
\hline Monitoring and evaluation &
\end{tabular}

$\mathrm{SOP}=$ standard operating procedure.

Source: World Health Organization. Laboratory Quality Standards and Their Implementation. https://apps.who.int/iris/bitstream/handle/10665/205405/ B4741.pdf? sequence=1. (accessed 10 February 2020). 


\section{ELEMENTS OF A QUALITY FRAMEWORK FOR HEALTH SERVICES}

Quality framework has several elements, all of which need to be addressed simultaneously to obtain comprehensive results. Most of these are described below:

(i) Systems approach. A quality system should be an integral part of health systems as part of a holistic approach.

(ii) Client focus. Expectations of clients including patients, beneficiaries, and the community at large should be met or surpassed in the context of access, affordability, and dignified and user-friendly services.

(iii) Recognizing champions. Generating and disseminating success stories, role models, inspirational leaders, and champions are intrinsic to spread a culture of quality.

(iv) Teamwork. Coordinated operations by policy makers, health administrators, clinicians, patient care staff, or frontline community health workers are needed to work together as a team.

(v) Process focus. Infrastructure and human resource should be optimized to ensure efficient processes leading to desired outcomes.

(vi) Continual improvement. Quality is a continuous journey in which every step can be made more effective and efficient through a continuous quality improvement cycle.

(vii) Objective quality measurement. Monitoring and evaluation using assessment tools and scoring system are an integral part of any quality system to assess improvements and bridge deficiencies. (viii) Concern and context. This involves improvement of quality and making it available to poor and vulnerable sectors of society in the form of expected services.

These elements are possible only when suggested actions are undertaken by various stakeholders as given in Table 2 .

Building quality health services requires a systematic approach and a culture of transparency, engagement, and openness about results. Evidence suggests that quality costs, but poor quality costs more. Substandard care wastes significant resources and harms the health of populations, destroys human capital, and reduces productivity.

Quality does not come automatically; it requires planning and should be a clearly identified priority of universal health care, along with access, coverage, and financial protection.

\section{QUALITY AND INDIA'S NATIONAL HEALTH POLICY}

The National Health Policy of India of 2017 enunciates improvements in health status through concentrated policy action in all sectors; and by expanding preventive, promotive, curative, palliative, and rehabilitative services provided through the public health sector, with focus on quality. ${ }^{13}$

Flowing from the National Health Policy, quality of health care has emerged as a key thrust for both policy makers and public

\section{Table 2: Actions by Key Stakeholders to Ensure Quality in Health Services}

\begin{tabular}{|c|c|}
\hline National Governments & Health System \\
\hline $\begin{array}{l}\text { - } \quad \text { Establish a national quality policy and implementation strategy } \\
\text { - } \quad \text { Brticulate commitment for delivering high-quality service } \\
\text { - } \quad \text { universal health care } \\
\text { - } \quad \text { Strengure that health systems perform as per quality standards } \\
\text { - } \quad \text { Create and sustain a health professional workforce } \\
\text { - } \quad \text { Finance quality improvement research } \\
\text { - Support continuous quality improvement }\end{array}$ & $\begin{array}{l}\text { - Implement evidence-based interventions } \\
\text { - } \quad \text { Promote infection control practices } \\
\text { health security threats through focused attention } \\
\text { on quality } \\
\text { - Put in place the infrastructure for continuous learning } \\
\text { Provide technical assistance and knowledge } \\
\text { management for improvement }\end{array}$ \\
\hline \multicolumn{2}{|l|}{ Community } \\
\hline $\begin{array}{l}\text { - Be empowered to actively engage in care to optimize their health status } \\
\text { Play a leading role in the design of new models of care to meet the } \\
\text { needs of the local community } \\
\text { Be informed that it is their right to have access to care that meets } \\
\text { achievable, modern standards of quality } \\
\text { Receive support, information, and skills to manage their own } \\
\text { long-term conditions }\end{array}$ & $\begin{array}{l}\text { Participate in quality measurement and improvement } \\
\text { with their patients } \\
\text { Embrace and practice a philosophy of teamwork and } \\
\text { meeting quality standards } \\
\text { - See patients as partners in the delivery of care } \\
\text { - Commit themselves to providing and using data to } \\
\text { demonstrate the effectiveness and safety of care } \\
\text { Engage in continuous quality improvement }\end{array}$ \\
\hline
\end{tabular}

Source: Adapted from World Health Organization, Organisation for Economic Co-operation and Development, and The World Bank. 2018. Delivering Quality Health Services: A Global Imperative for Universal Health Coverage. Geneva.

13 Government of India, Ministry of Health and Family Welfare. National Health Policy 2017. https://www.nhp.gov.in/nhpfiles/national_health_policy_2017.pdf. 
health practitioners, and as an instrument of optimal utilization of resources and improving health outcomes and client satisfaction. Accordingly, the National Urban Health Mission of India has developed a road map for improving the quality of its health services.

\section{QUALITY IN NATIONAL URBAN HEALTH MISSION}

The National Urban Health Mission has been striving to provide quality health care to all citizens of India in an equitable manner. After launch of this road map, various models and approaches were tried for assuring quality in health services, although in a fragmented manner.

In 2008, the National Health Systems Resource Centre adopted and implemented ISO 9001:2008 - Quality Management System in a few public health facilities across the country. Recognizing the urgent need for quality in all services, the Ministry of Health and Family Welfare in 2012 embarked on a comprehensive system of quality assurance at public health facilities. Table 3 lists the milestones of the National Urban Health Mission in integrating quality.

The National Quality Assurance Standards (NQAS) are broadly arranged under eight "Areas of Concern"-Service Provision, Patient Rights, Inputs, Support Services, Clinical Care, Infection Control, Quality Management, and Outcome. These standards

\section{Table 3: Milestones in Integrating Quality in National Urban Health Mission}

\begin{tabular}{crl} 
No. & Year & \multicolumn{1}{c}{ Milestone Achieved } \\
\hline 1 & 2008 & $\begin{array}{l}\text { National Health Systems Resource Centre adopts } \\
\text { ISO 9001:2008 }\end{array}$ \\
\hline 2 & 2012 & $\begin{array}{l}\text { Government of India commits need for quality in health } \\
\text { services }\end{array}$ \\
\hline 3 & 2013 & Operational Guidelines for Quality Assurance developed \\
\hline 4 & 2013 & Quality standards for district hospitals published \\
\hline 5 & 2014 & $\begin{array}{l}\text { Quality standards for primary health centers and } \\
\text { community health centers developed }\end{array}$ \\
\hline 6 & 2015 & $\begin{array}{l}\text { International recognition of quality system accorded by } \\
\text { ISQua }\end{array}$ \\
\hline 7 & 2016 & $\begin{array}{l}\text { Quality standards for urban primary health centers } \\
\text { developed (revised 2018) }\end{array}$ \\
\hline 8 & 2018 & \begin{tabular}{l} 
External Assessor Training Program accredited by ISQua \\
\hline
\end{tabular} \\
\hline
\end{tabular}

ISQua = International Society for Quality in Healthcare.

Source: Asian Development Bank. meet global benchmarks in terms of comprehensiveness, objectivity, evidence and rigor of development. NQAS received accreditation from the International Society for Quality in Healthcare in 2015. The External Assessor Training program also received international accreditation from International Society for Quality in Healthcare in 2018.

The National Urban Health Mission has a built-in system of assessment of urban health facilities, followed by action planning for traversing the observed gaps. Feedback from the patients, preferably through the platform of "Mera-Aspataal", 14 are collected and analyzed for appropriate actions.

Likewise, a provision of encouragement through incentives for achievement and sustenance of quality has been integrated into the operations. Facilities that obtain $70 \%$ of scoring against standards are certified and receive incentives.

Accordingly, to meet the state benchmark, the states seek national quality certification administered by the empaneled NQAS assessors. If certified for quality, health facilities are incentivized at ₹3,00,000 (approximately \$4,500) for bedded and $₹ 2,00,000$ (approximately $\$ 3,000$ ) for nonbedded urban primary health centers in the first year, and also in the subsequent years upon demonstration of sustaining the improvement process.

The quality program across the country is monitored by the central quality supervisory committee in the Ministry of Health and Family Welfare, and by the quality assurance committees at the state and district level. During the past few years, several structural and functional achievements have been made under the National Quality Assurance Program. In India, the National Urban Health Mission was drafted as a road map toward improving the quality of health services for the urban poor as part of the country's efforts to provide universal health care.

\section{NATIONAL ROAD MAP FOR IMPROVING THE QUALITY OF HEALTH CARE}

The National Urban Health Mission has articulated the following elements to ensure quality of health services in urban settings: ${ }^{15}$

(i) a quality policy and programmatic approach as part of the formal health sector national plan;

(ii) a quality policy document developed as a stand-alone national document, usually within a multistakeholder process, led or supported by the health ministry;

(iii) a national quality implementation strategy — with a detailed action agenda-which also includes a section on essential policy areas; and

(iv) enabling legislation and regulatory statutes to support the policy and implementation strategy.

\footnotetext{
14 National Health Portal of India. Mera Aspataal. https://www.nhp.gov.in/mobile-mera-aspataal (accessed 30 January 2020).
}

15 National Health Systems Resource Centre. http://qi.nhsrcindia.org/. 


\section{FRAMEWORK FOR IMPLEMENTING QUALITY}

Implementation of the road map is through the framework of quality assurance. The framework comprises four interrelated approaches and activities to achieve a patient-centric quality system: (i) instituting organizational framework for quality, (ii) defining standards of service delivery and patient care, (iii) continuous assessment of services against set standards, and (iv) improving quality through closing gaps and implementing opportunities for improvement.

\section{KEY FEATURES OF QUALITY ASSURANCE IN THE NATIONAL URBAN HEALTH MISSION}

An efficient quality assurance system in urban health care services through a unified organizational framework at the national, state, and district level, and its integration with the existing health care delivery system, is currently operating in India. ${ }^{16}$ The National Quality Assurance Programme has devised a functional and explicit measurement system where facilities are assessed in eight critical areas, namely, service provision, patient rights, inputs, support services, clinical services, infection control, quality management system, and outcome. In addition, training and capacity building of program units and facilities for assessment, implementation, and certification are frequently undertaken. These activities are followed by continuous assessment by facilities and program units at defined intervals to ensure that quality services are being provided to all.

The system is designed in such a way that each facility opting for it must go for quality improvement activities including planning, assessments, generation of score cards, gap finding and reporting of key performance indicators, and certification.

Both internal and external (third-party) assessments of the quality system have been built into the National Urban Health Mission. Assessments are not fault-finding activities. These are fact-finding steps that help immensely in improving quality. They detect errors and suggest management responses and technical solutions to resolve these. Quality is an ongoing process without any defined endpoint, and continuous quality improvement is the mantra for success.

\section{SALIENT FEATURES OF INDIA'S NATIONAL QUALITY ASSURANCE PROGRAM FOR HEALTH}

The National Quality Assurance Program has been designed to improve the quality of health services provided in public facilities. In a span of 6-7 years, this program has conclusively demonstrated its efficacy and utility. Integrating the quality dimension has enhanced the credibility and sustainability of health services.

The initial successful results with implementation of the National Quality Assurance Program have been encouraging and indicate that there is a great potential and need for expansion in health services in all urban areas of India (see success stories in Box 1 and Box 2).

Linkages between the quality system in urban health services with ongoing and politically strongly supported initiatives such as Kayakalp; Swachh Bharat Abhiyan; and Swachh, Swasth, and Sarvatra campaigns have yielded greater benefits. A clean environment within a health facility gives confidence to patients, encourages them to revisit, and improves credibility of the facility as well as the health system.

\section{CONCLUSIONS}

Implementing quality in all health services under the National Urban Health Mission has improved health services. This has also enhanced the program's credibility among the communities. Already, there are several success stories across the country. Nevertheless, quality improvement is a continuous process as articulated through the Deming cycle. National efforts to sustain quality in health services must be sustained and incrementally augmented to strengthen universal health care, especially for the vulnerable poor in urban settings.

\footnotetext{
16 See National Health Systems Resource Centre. QA under National Urban Health Mission. http://qi.nhsrcindia.org/qa-under-national-urban-health-mission.
} 


\section{Box 1: Improving Quality of Diagnostic Laboratories- A Success Story under the National Urban Health Mission}

Quality in laboratory services is critical to generate reliable results that influence appropriate management of patients. Around $70 \%$ of all clinical decisions in hospitals are based on laboratory test results. While corporate and tertiary care hospitals have accorded priority to quality in their services, health laboratories in peripheral health facilities have remained mostly neglected.

Under a pilot partnership between the Labs for Life Project (L4L), Ministry of Health and Family Welfare, Centers for Disease Control and Prevention, Becton Dickinson and Company, and Christian Medical Association of India, quality system was strengthened in laboratories of the Paota Hospital, Jodhpur District, Rajasthan. This health facility is a 150-bed hospital and caters to a population within a radius of 25 kilometers. The hospital laboratory provides 52 out of 56 tests as per Rajasthan's Mukhyamantri Nishulk Janch Yojana scheme. ${ }^{a}$

Before the commencement of the $\mathrm{L} 4 \mathrm{~L}$ project, laboratory services in the Paota District Hospital were perceived just as a routine support service, not as a core clinical activity that has a huge influence on patient outcomes. Consequently, insufficient attention was given to the quality of laboratory services, in spite of having adequate equipment and supplies.

The L4L project provided technical capacity building, resource mobilization, and advocacy. The capacity building and skilling of the workforce through on-site and offsite trainings, mentoring, supportive supervision, and e-learning through webinars was the mainstay of the project. The areas of training covered in 1 year were sample collection, equipment management, facility management and safety, documentation, nonconforming event management, assessments and evaluations, quality controls, etc.

The assessment of the laboratories was undertaken following ISO 15189; as well as Checklist 13 for Laboratories of the National Quality Assurance Standards. The quality system requirements under ISO 15189 include safe sample collection, equipment management, facility management and safety, documentation, instituting error detection mechanisms through quality controls, staff training and development, nonconforming event management, assessments, and evaluation.

A baseline situation analysis undertaken in February 2015 revealed the gaps and challenges in terms of service provision, patient rights, inputs, support services, clinical services, infection control, quality management, and outcome measurement. The laboratory obtained an overall score of 27.2\%. A midterm assessment in October 2016 showed significant improvement. The laboratory scored 59.7\%, a 119\% increase that clearly indicates the effectiveness of the $\mathrm{L} 4 \mathrm{~L}$ program in improving various components (Figure A).

The improvement in quality services was achieved without much additional investment, by ensuring effective resource utilization and by tapping into available funds. Encouraged by this success, a National Initiative toward ISO-based quality improvement programs is being considered.
It was also observed that apart from improving skills of the workforce for efficient and effective laboratory performance, several nontechnical factors that influenced the institution of a quality management system include the attitude and willingness of laboratory staff to adapt to advances in laboratory medicine and team building (Figure B).

\section{Figure A: Improvement in Paota District Hospital under the Labs for Life Project (\%)}

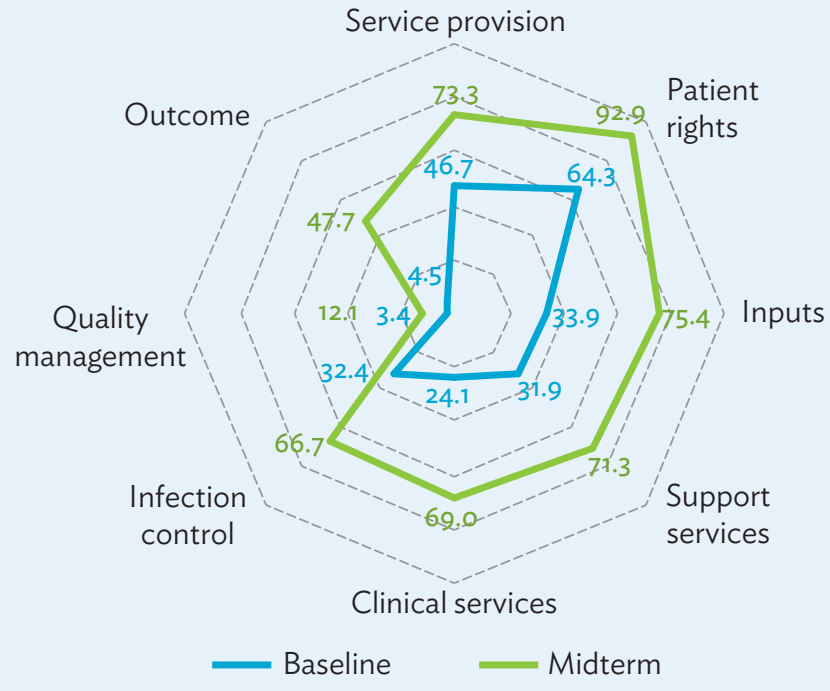

\section{Figure B: Nontechnical Aspects that Expedited Improvement in Laboratory Services in Paota District Hospital}

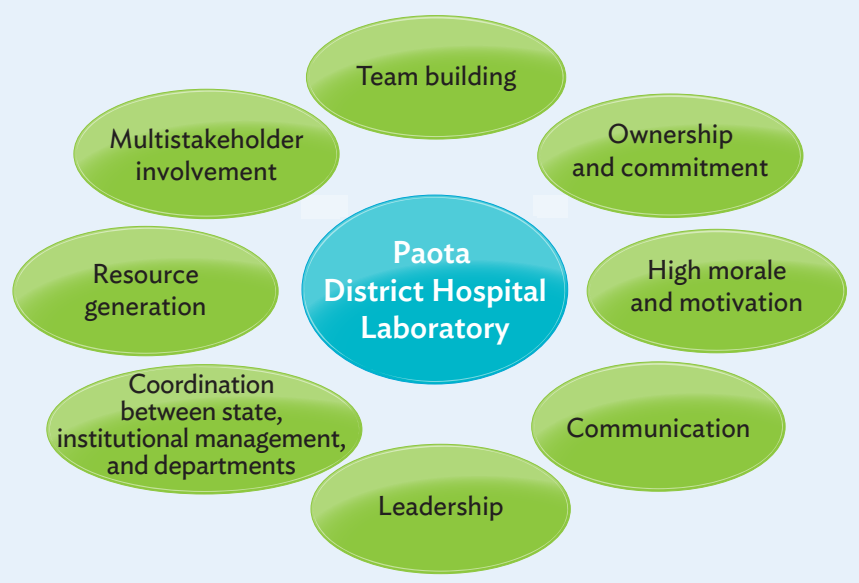

a Government of Rajasthan, Rajasthan Medical Services Corporation Limited. Mukhyamantri Nishulk Janch Yojana. http://rmsc.health. rajasthan.gov.in/content/raj/medical/rajasthan-medical-servicescorporation-Itd-/en/services/MNJYO.html (accessed 8 February 2020). Sources: National Health Systems Resource Centre and Ministry of Health and Family Welfare. 


\section{Box 2: Improving Quality of Care in Krishna Nagar, Haryana}

The urban primary health center (UPHC) Krishna Nagar Gamri is located in the historic city of Kurukshetra in Haryana. It was the first UPHC in the country to receive National Quality Assurance Standard (NQAS) certification in February 2018.

The quality system was implemented through a systematic and continuous approach. The medical officer in charge of this UPHC took the leadership and ownership to bring changes in the quality of care through implementation of National Quality Assurance Program. All checkpoints of quality assurance standards of UPHCs were reviewed and staff were oriented on these. A quality team at $\mathrm{UPHC}$ was formed to respond to every challenge.

Skills development among the staff was undertaken through regular trainings and interactions almost on a daily basis. Staff was sensitized that this is not a separate program demanding additional time but includes all efforts that provide patient satisfaction. Through active cooperation of the staff and the management, the measures taken for improvement became sustainable. Gradually these became daily habits for the staff.

The whole program was successful due to teamwork. Many innovative ideas were developed and implemented. Some of these were (i) creating a NQAS register for calculation of all key performance indicators and monthly review of their trends; (ii) appreciating staff who have done any exemplary work or provided any innovative approach for problem solving during a month; (iii) posting pictorial and locally relevant information, education, and communication material at a strategic place of UPHC for greater visibility; and (iv) segregating look-alike and sound-alike medicine to avoid any confusion.

In addition, process mapping was undertaken to enhance efficiency. A dedicated facility was set up per Kayakalp guidelines and made operational for management of liquid waste in the UPHC itself.

The journey for implementation of NQAS was difficult and challenging, but commitment and leadership of the medical officer, collective teamwork of the staff, and innovative approaches for any problem yielded the desired results. This culminated in public satisfaction with services, error-free dispensing of medicines, collaborative activities with staff who have been oriented, quality as the central theme through leadership leading to professional satisfaction, and delivery of quality services to intended consumers.

Sources: National Health Systems Resource Centre and Ministry of Health and Family Welfare.
About the Asian Development Bank

$A D B$ is committed to achieving a prosperous, inclusive, resilient, and sustainable Asia and the Pacific, while sustaining its efforts to eradicate extreme poverty. Established in 1966, it is owned by 68 members49 from the region. Its main instruments for helping its developing member countries are policy dialogue, loans, equity investments, guarantees, grants, and technical assistance.

ADB Briefs are based on papers or notes prepared by ADB staff and their resource persons. The series is designed to provide concise, nontechnical accounts of policy issues of topical interest, with a view to facilitating informed debate. The Department of Communications administers the series.

Note: In this publication, “\$” refers to United States dollars and “₹” to Indian rupees.
The views expressed in this publication are those of the authors and do not necessarily reflect the views and policies of ADB or its Board of Governors or the governments they represent. ADB encourages printing or copying information exclusively for personal and noncommercial use with proper acknowledgment of ADB. Users are restricted from reselling, redistributing, or creating derivative works for commercial purposes without the express, written consent of ADB.

Asian Development Bank

6 ADB Avenue, Mandaluyong City

1550 Metro Manila, Philippines

Tel +63286324444

Fax +63286362444

www.adb.org/publications/series/adb-briefs 